\title{
Responses of FEV 6 , FVC, and FET to inhaled bronchodilator in the adult general population
}

\author{
Annette Kainu*1, Ari Lindqvist ${ }^{2,3}$, Seppo Sarna ${ }^{4}$, Bo Lundbäck ${ }^{5}$ and \\ Anssi Sovijärvi 6
}

Address: ${ }^{1}$ Division of Pulmonary Medicine, Department of Medicine, Helsinki University Central Hospital, PO Box 340 , FIN-00029 HUS, Helsinki, Finland, ${ }^{2}$ Research Unit of Pulmonary Diseases, Department of Medicine, Helsinki University Central Hospital, ${ }^{3} \mathrm{Clinical}$ Research Institute Ltd, Helsinki, Finland, ${ }^{4}$ Department of Public Health, University of Helsinki, Helsinki, Finland, ${ }^{5}$ Department of Internal Medicine/ Respiratory Medicine and Allergology, Sahlgrenska Academy, University of Gothenburg, Sweden and ${ }^{\circ}$ Division of Clinical Physiology and Nuclear Medicine, Laboratory Department, Helsinki University Central Hospital, Helsinki, Finland

Email: Annette Kainu* - annette.kainu@fimnet.fi; Ari Lindqvist - ari.lindqvist@hus.fi; Seppo Sarna - seppo.sarna@helsinki.fi; Bo Lundbäck - bo.lundback@gu.se; Anssi Sovijärvi - anssi.sovijarvi@hus.fi

* Corresponding author

Published: 28 July 2009

Respiratory Research 2009, 10:7| doi:10.1186/|465-992I-10-7|
Received: 29 September 2008

Accepted: 28 July 2009

This article is available from: http://respiratory-research.com/content/I0/I/7I

(c) 2009 Kainu et al; licensee BioMed Central Ltd.

This is an Open Access article distributed under the terms of the Creative Commons Attribution License (http://creativecommons.org/licenses/by/2.0), which permits unrestricted use, distribution, and reproduction in any medium, provided the original work is properly cited.

\begin{abstract}
Background: The assessment of bronchodilator-induced change in forced vital capacity (FVC) is dependent on forced expiratory time (FET) in subjects with airflow limitation. Limited information is available on the concurrent responses of FVC, forced expiratory volume in six seconds $\left(\mathrm{FEV}_{6}\right)$, and FET in the bronchodilation test among patients with obstructive airways disease or in the general population. The aim of this study was to assess the changes in $\mathrm{FEV}_{6}, \mathrm{FVC}$, and FET, and their relationships in a standardized bronchodilation test in the general population.
\end{abstract}

Methods: We studied bronchodilation response in a general adult population sample of 628 individuals (260 men, 368 women) with flow-volume spirometry. The largest FVC, the corresponding FET and the largest $\mathrm{FEV}_{6}$ both at the baseline and after $0.4 \mathrm{mg}$ of inhaled salbutamol were selected for analysis.

Results: After administration of salbutamol $\mathrm{FEV}_{6}$ decreased on average $-13.4(95 \% \mathrm{Cl}-22.3$ to $4.5) \mathrm{ml}$ or $-0.2 \%(-0.4 \%$ to $0.0 \%)$ from the baseline. The $95^{\text {th }}$ percentile of change in $\mathrm{FEV}_{6}$ was 169.1 $\mathrm{ml}$ and $5.0 \%$. FVC decreased on average $-42.8(-52.4$ to -33.3$) \mathrm{ml}$ or $-1.0 \%(-1.2 \%$ to $-0.7 \%)$. Concurrently FET changed on average $-0.2(-0.4$ to 0.0$)$ seconds or $0.4 \%$ (-I.4\% to $2.3 \%)$. There were four subjects with an increase of FVC over $12 \%$ and only one of these was associated with prolonged FET after salbutamol. Changes in $\mathrm{FEV}_{6}$ and FVC were more frequently positive in subjects with reduced $\mathrm{FEV} / \mathrm{FVC}$ in baseline spirometry.

Conclusion: In general adult population, both $\mathrm{FEV}_{6}$ and FVC tended to decrease, but FET remained almost unchanged, in the bronchodilation test. However, those subjects with signs of airflow limitation at the baseline showed frequently some increase of $\mathrm{FEV}_{6}$ and $\mathrm{FVC}$ in the bronchodilation test without change in FET. We suggest that $\mathrm{FEV}_{6}$ could be used in assessment of bronchodilation response in lieu of FVC removing the need for regulation of FET during bronchodilation testing. 


\section{Introduction}

In recent years forced expiratory volume in six seconds $\left(\mathrm{FEV}_{6}\right)$ has evolved as a novel parameter in flow-volume spirometry that has been suggested to replace forced vital capacity (FVC) for some clinical applications [1-4]. A practical benefit of using $\mathrm{FEV}_{6}$ would be easier performance by patients because maximal end-expiration can be avoided. This measure could especially lend itself for use in the primary care setting [1]. Reference values and data on reliability and utility in the diagnosis of obstructive and restrictive lung diseases are emerging for $\mathrm{FEV}_{6}$ [2-9].

Bronchodilation induced by pharmacological agents is an important feature of asthma, whereas chronic obstructive pulmonary disease (COPD) is characterized by chronic airflow limitation that is not fully reversible [10]. In COPD, bronchodilation response may be reflected as increase of FVC, as an indicator of relief of air trapping $[11,12]$. The FVC manoeuvre is technically demanding, significantly affected by expiratory time in subjects with airflow limitation, and sensitive to the impact of tiring [13].

The joint American Thoracic Society (ATS) and European Respiratory Society (ERS) Task Force on Standardisation of Lung Function Testing recommended in 2005 that a $12 \%$ and $200 \mathrm{ml}$ improvement in either $\mathrm{FEV}_{1}$ or FVC from baseline would be considered a significant bronchodilation response [14]. Recently we have shown that $\mathrm{FEV}_{1}$ response to bronchodilation by around $9 \%$ from the baseline in an adult urban population is significant [15]. If bronchodilation response is observed only in $\mathrm{FVC}$, the concurrent change in forced expiratory time (FET) should be evaluated [14]. Based on the observed intra-session variability of FET in the general population, we have suggested that 3 seconds would constitute a significant change [16]. In subjects with airflow limitation the intrasession repeatability of $\mathrm{FEV}_{6}$ was at least equal to the repeatability of FVC [16]. $\mathrm{FEV}_{6}$ is the least variable of the FEVx [17]. Both $\mathrm{FEV}_{3}$ and $\mathrm{FEV}_{6}$ have been shown to increase significantly when the increase in FVC was not caused by longer exhalation time [18]. Standardisation of FET during bronchodilation testing is problematic. Since $\mathrm{FEV}_{6}$ would offer better repeatability and an unequivocal end-of-test measure, it would be interesting to assess $\mathrm{FEV}_{6}$ as a surrogate measure of FVC response in the bronchodilation test.

The aim of this study was to evaluate the concurrent changes in $\mathrm{FEV}_{6}, \mathrm{FVC}$, and FET in a standardized bronchodilation test and their association with airflow limitation in a general adult population sample using flowvolume spirometry. Furthermore, the role of $\mathrm{FEV}_{6}$ as a surrogate of FVC in the bronchodilation test was evaluated.

\section{Materials and methods Subjects}

In 1995 the original sample of 8000 adults aged 20-69 years was randomly selected from the Finnish Population Registre Center to represent the adult population of Helsinki, Finland. Randomization was stratified by gender and 10-year age cohorts. In phase I a postal questionnaire study was completed, with 6062 responders. In 2000 a further random sample of 1200 subjects were sampled from the original postal questionnaire responders to a subsequent clinical study. During 2000-2003 a total of 643 subjects participated in phase II of the FinEsS-Helsinki study. The study protocol has been reported in previous articles $[15,16,19]$.

In this study, 628 acceptable spirometric measurements (260 for men, 368 for women) with bronchodilation testing and a structured interview were completed. Study subjects were interviewed using a structured questionnaire to obtain information about general health, respiratory illnesses, medications and environmental exposures. The Finnish FinEsS structured interview has been developed from the OLIN questionnaire $[20,21]$.

The study was conducted according to the Helsinki Declaration and approved by the Ethics Committee of the Department of Medicine of Helsinki University Central Hospital. All participants gave informed consent.

\section{Measurements}

Spirometry procedures were based on the 1994 recommendation of the American Thoracic Society [22], with the exception of repeatability criteria that were based on modified ERS criteria [23]. The two largest $\mathrm{FEV}_{1}$ and FVC were required to be within $150 \mathrm{ml}$ or $5 \%$ of the respective volume, whichever was greater, and the two largest peak expiratory flows (PEF) were required to be within $10 \%$.

Spirometry was completed with a flow-volume spirometry device (VMax 20c, Sensor Medics, Yorba Linda, CA, USA) with the patient seated. Each subject performed three to eight forced expiratory manoeuvres and inspiratory spirograms were recorded in conjunction with expiratory spirograms whenever feasible. In the bronchodilation test the subjects inhaled $0.4 \mathrm{mg}$ of salbutamol aerosol (Ventoline $0.2 \mathrm{mg}$, GlaxoSmithKline, London, UK) through a spacer device (Volumatic, GlaxoSmithKline, London, UK) on two separate doses and spirometry was repeated after 15 minutes rest. Spirometry was evaluated using the current Finnish reference values, which do not yet contain reference values for $\mathrm{FEV}_{6}[24]$. The detailed spirometry procedure has been published previously $[15,16]$. 
The spirometry variables evaluated in this study were $\mathrm{FVC}$ FEV $_{6}$ and FET. The largest $\mathrm{FEV}_{6}$ and FVC from the acceptable pre- and post-bronchodilation curves, and the FET measured from the curve with the largest FVC were selected for analysis. The FET defined and recorded by the spirometer software was used (Vision Software 05-2A, Vmax System, Sensor Medics, Yorba Linda, CA, USA). The beginning point of measurement is the back extrapolated time zero $[14,25]$ and the end-point at the beginning of the end-expiratory plateau. In cases where the total exhalation time recorded by the spirometer was under six seconds, the FVC was used in lieu of $\mathrm{FEV}_{6}$. The difference between baseline spirometry and post-bronchodilator spirometry was assessed using both absolute change and change relative to baseline spirometry.

The smoking history was evaluated from the structured interview and subjects were categorized into never-smokers, former smokers and current smokers in addition to calculating smoking pack-years for the ever-smokers. Former smokers were required to have stopped smoking at least 12 months prior to the study. Previously published criteria based on the structured interview were used to define a subgroup of healthy asymptomatic non-smokers $[15,20]$ to assess the upper limit of normal. The anthropometric parameters analysed were gender, age, height, weight, and body mass index (BMI, $\mathrm{kg} / \mathrm{m}^{2}$ ). The descriptive statistics of the study population including baseline spirometric results and smoking history are outlined in Table 1.

\section{Analysis}

Statistical analyses were performed with SPSS for Windows (version 15.01; SPSS, Chicago, IL, USA). Distribution of parameters was assessed using scatter graphs and normality was assessed with the Kolmogorov-Smirnov test for normality. Pearson correlation coefficient ( $r$ ) was used to assess the correlation of changes in FVC and $\mathrm{FEV}_{6}$ with FET. The intra-class correlation coefficient was used to assess the agreement between change in $\mathrm{FVC}$ and $\mathrm{FEV}_{6}$ using a one-way random effects model $[26,27]$. The intraclass correlation coefficient produces measures of consistency or agreement of values within cases. Analysis of variance (ANOVA) was used for categorical comparisons. The method described by Bland \& Altman [28] was modified to demonstrate dependence of change in FVC and FET of their respective average values [29]. P-values less than 0.05 were considered statistically significant for all other analyses, except for correlations, for which a p-value less than 0.01 was regarded significant. All analyses were twosided unless otherwise indicated.

\section{Results}

Changes in FVC and $\mathrm{FEV}_{6}$ in bronchodilation test were normally distributed. The concurrent changes in $\mathrm{FEV}_{6}$, FVC and FET in the bronchodilation test are outlined in Table $2 . \mathrm{FEV}_{6}$ decreased statistically significantly more in women both in absolute and in relative terms, whereas the gender difference was only significant in relative change in FVC. Change of FVC and FET in relation to their respective average values are shown in Figure 1 in a mod-

Table I: Anthropometric and baseline spirometric statistics of the study population

\begin{tabular}{|c|c|c|c|c|c|c|}
\hline & \multicolumn{3}{|c|}{ men $(n=260)$} & \multicolumn{3}{|c|}{ women $(n=368)$} \\
\hline & mean (SD) & $95 \% \mathrm{Cl}$ & range & mean (SD) & $95 \% \mathrm{Cl}$ & range \\
\hline age [yrs] & $48.6(12.7)$ & $47.0-50.1$ & $26.3-74.2$ & $49.5(13.2)$ & $48.2-50.9$ & $25.7-74.4$ \\
\hline height $[\mathrm{m}]$ & $1.78(0.07)$ & $1.77-1.79$ & $1.62-1.98$ & $1.64(0.06)$ & $1.63-1.64$ & $1.46-1.83$ \\
\hline weight $[\mathrm{kg}]$ & $83.9(14.1)$ & $82.2-85.6$ & $52.4-139.0$ & $68.8(13.7)$ & $67.4-70.2$ & $44.0-133.0$ \\
\hline $\mathrm{BMI}\left[\mathrm{kg} / \mathrm{m}^{2}\right]$ & $26.5(4.3)$ & $26.0-27.0$ & $17.1-44.9$ & $25.7(5.1)$ & $25.2-26.2$ & $16.9-53.3$ \\
\hline baseline FVC [l] & $5.075(0.911)$ & $4.964-5.187$ & $2.182-8.033$ & $3.549(0.660)$ & $3.482-3.617$ & $2.013-5.388$ \\
\hline baseline FVC \% of reference* & $98.1(12.3)$ & $96.6-99.6$ & $50.8-131.2$ & $99.5(12.5)$ & $98.2-100.7$ & $71.9-144.6$ \\
\hline baseline $F E V_{1}[l]$ & $3.897(0.832)$ & $3.795-3.999$ & $1.016-5.895$ & $2.784(0.591)$ & $2.724-2.845$ & $0.992-4.495$ \\
\hline baseline $\mathrm{FEV}_{1} \%$ of reference* & $92.9(14.9)$ & $91.0-94.7$ & $29.3-128.7$ & $94.7(13.1)$ & $93.3-96.0$ & $40.6-132.8$ \\
\hline baseline $\mathrm{FEV}_{6}[]^{* *}$ & $4.888(0.937)$ & $4.774-5.002$ & $2.14-7.75$ & $3.437(0.675)$ & $3.368-3.506$ & $|.84-5.3|$ \\
\hline baseline FET $[\mathrm{s}] \pm$ & II.5 (4.3) & $|1.0-12|$. & $1.6-37.0$ & $10.5(4.5)$ & $10.0-10.9$ & $1.7-36.8$ \\
\hline baseline $\mathrm{FEV}_{\mathrm{l}} / \mathrm{FVC}[\%]$ & $76.5(7.8)$ & $75.5-77.5$ & $34.8-96.3$ & $78.3(7.0)$ & $77.6-79.0$ & 44.7-92.9 \\
\hline \multirow[t]{2}{*}{ baseline $\mathrm{FEV} / \mathrm{FVC} \%$ of reference* } & $94.5(9.6)$ & $93.4-95.7$ & $42.6-121.2$ & $95.3(8.0)$ & $94.5-96.1$ & $55.1-114.9$ \\
\hline & & $\begin{array}{l}\text { pack-years } \\
\text { mean (SD) }\end{array}$ & range & & $\begin{array}{l}\text { pack-years } \\
\text { mean (SD) }\end{array}$ & range \\
\hline non-smokerst & $\mathrm{n}=112$ & n.a. & n.a. & $n=226$ & n.a. & n.a. \\
\hline former smokers & $n=59$ & $23.6(16.9)$ & $5.5-82.5$ & $\mathrm{n}=49$ & $18.0(13.7)$ & $1.2-66.0$ \\
\hline current smokers & $n=89$ & $26.2(22.0)$ & $0.4-95.0$ & $n=93$ & $19.1(16.0)$ & $0.6-86.0$ \\
\hline
\end{tabular}

$\mathrm{BMI}=$ body mass index; $\mathrm{FVC}=$ forced vital capacity; $F E V_{1}=$ forced expiratory volume in one second; $\mathrm{FEV}_{6}=$ forced expiratory volume in six seconds; FET = forced expiratory time; n.a. = not applicable

$*$ predicted values from [24]

** maximum value of acceptable curves

\pm value corresponding to largest FVC measurement

$\dagger$ including former smokers smoking under 5 pack-years and smoking cessation over 5 years previously 
ified Bland-Altman plot. At higher FVC there were less bronchodilation changes, but at higher FET more frequent changes associated with both underlying airflow limitation and poorer repeatability of FET in comparison to FVC. In the bronchodilation test $23.1 \%$ of men and $33.2 \%$ of women had a decrease of FVC greater than $2.5 \%$ from the baseline. The mean change in FVC was -42.8 (95\% CI -52.4 to -33.3 ) $\mathrm{ml}$ or $-1.0 \%$ ( $-1.2 \%$ to $-0.7 \%)$. The upper $95^{\text {th }}$ percentile for change in FVC was $137.0 \mathrm{ml}$ and $4.0 \%$. The mean change in FET was $-0.2(-0.4-0.0)$ seconds or $0.4 \%(-1.4 \%-2.3 \%)$, with a $95^{\text {th }}$ percentile of 3.4 seconds or $44.0 \%$.

$\mathrm{FEV}_{6}$ tended to decrease during bronchodilation test, but the mean reduction was less marked than in FVC (mean change -13.4 (-22.3 to -4.5$) \mathrm{ml}$ or $-0.2 \%(-0.4 \%-0.0 \%))$. The $95^{\text {th }}$ percentile for change in $\mathrm{FEV}_{6}$ was $169.1 \mathrm{ml}$ and $5.0 \%$. The individual concurrent changes in $\mathrm{FEV}_{6}$ and FVC are demonstrated in Figure 2. The intra-class correlation coefficient (ICC) for the concurrent absolute change in $\mathrm{FEV}_{6}$ and FVC was $0.84(0.82-0.87)$ and for the relative change $0.86(0.83-0.88)$. The agreement between changes in $\mathrm{FEV}_{6}$ and $\mathrm{FVC}$ was better in subjects with airways obstruction $\left(\mathrm{FEV}_{1} / \mathrm{FVC}\right.$ post-bronchodilator < LLN); ICC for the relative change in subjects with obstruction was $0.91(0.84-0.95)$ and in those who were non-obstructed 0.80 (0.77-0.83). Age, height, weight or BMI did not cor- relate significantly with changes in $\mathrm{FVC}, \mathrm{FEV}_{6}$ or FET during the bronchodilation test.

There were four subjects with the increase of FVC from the baseline at least $12 \%$ and $200 \mathrm{ml}$, yielding a population prevalence of $0.6 \%$ for a significant improvement of FVC in the bronchodilation test. Using the same threshold values six subjects showed a significant change of $\mathrm{FEV}_{6}$. The changes in $\mathrm{FVC}, \mathrm{FEV}_{6}, \mathrm{FEV}_{1}$ and $\mathrm{FET}$ of these subjects are individually shown in Table 3. One subject had a significant increase in $\mathrm{FVC}$, but an insignificant increase in $\mathrm{FEV}_{6}$; for her the increase of FVC was associated with an increase of FET by 8 seconds and $71 \%$ relative to the baseline FET. Three subjects had a significant increase in $\mathrm{FEV}_{6}$ but a smaller increase in FVC, which were associated to shorter FET in post-bronchodilator spirometry.

The relationship of individual changes of FVC and the difference between changes in $\mathrm{FEV}_{6}$ and FVC in bronchodilation test, to baseline $\mathrm{FEV}_{1} / \mathrm{FVC}$ is demonstrated in Figure 3. Increase of FVC in the bronchodilation test associated inversely with $\mathrm{FEV}_{1} / \mathrm{FVC}$ ratio and $\mathrm{FEV}_{1}$. The changes in flow-volume spirometry variables stratified by $\mathrm{FEV}_{1} / \mathrm{FVC}$ ratio at the baseline below or above lower limit of normal (LLN) are shown in Table 4. In subjects with airflow limitation the changes in $\mathrm{FEV}_{6}$ and FVC were on the average $+2.4 \%$ and $+0.8 \%$, respectively. In subjects with no air- a)

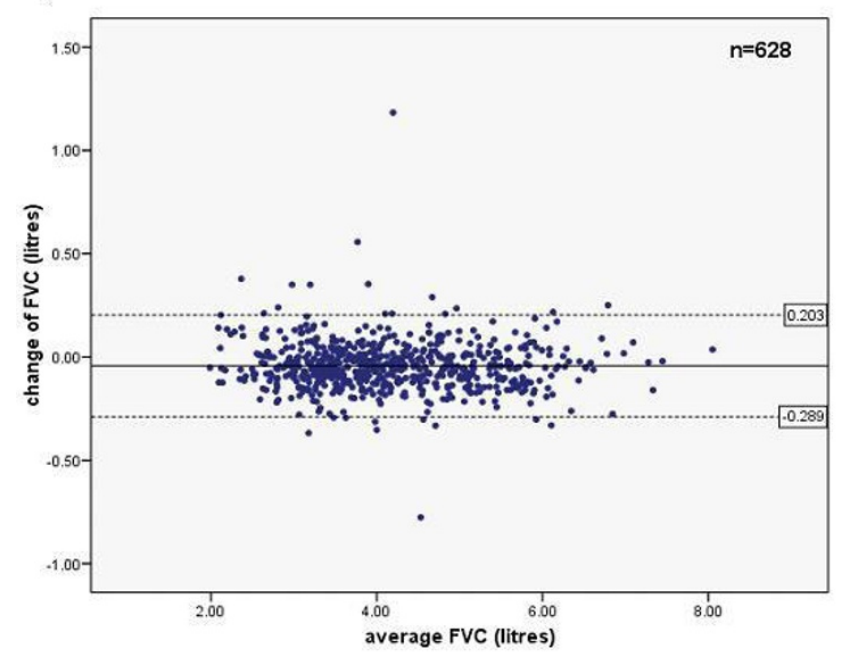

b)

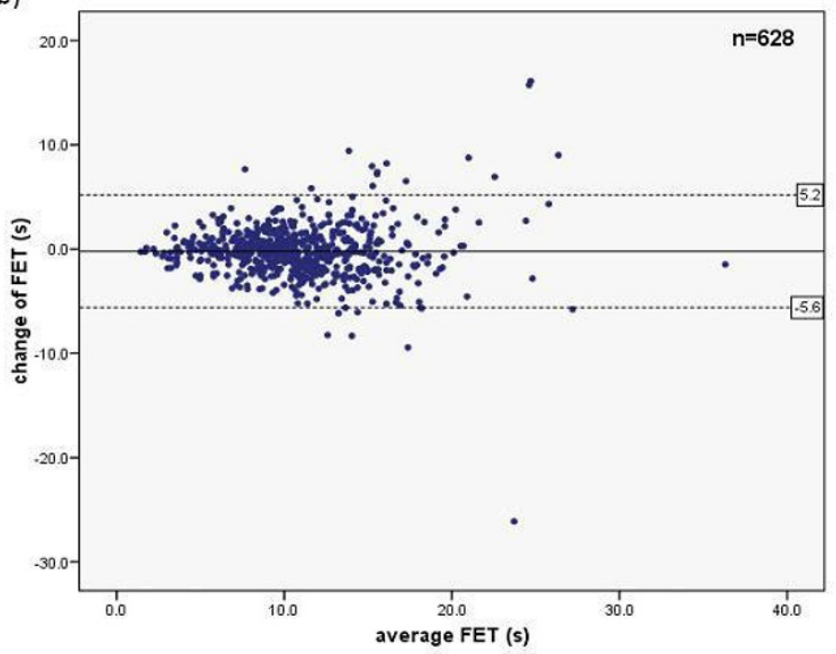

\section{Figure I}

Bland \& Altman graphs depicting: a) individual changes in forced vital capacity (FVC) in relation to average FVC, and b) individual changes in forced expiratory time (FET) in relation to average FET, in a bronchodilation test with salbutamol aerosol $0.4 \mathrm{mg}$ in the general adult population $(\mathbf{n}=\mathbf{6 2 8})$. The dotted lines indicate the 2 SD limits from the respective mean value. Larger bronchodilation responses in FVC were seen in subjects with lower FVC and larger variation in FET with prolonged FET, which was associated to more severe obstruction. 
Table 2: Concurrent changes in forced expiratory volume in one $\left(F E V_{1}\right)$ and six $\left(F E V_{6}\right)$ seconds, forced vital capacity (FVC) and forced expiratory time (FET) in the bronchodilation test in general population

\begin{tabular}{|c|c|c|c|c|c|c|c|}
\hline & \multirow[b]{2}{*}{ mean $(S D)$} & \multicolumn{2}{|l|}{ men $(n=260)$} & \multicolumn{3}{|c|}{ women $(n=368)$} & \multirow[b]{2}{*}{$\begin{array}{l}\text { gender difference } \\
\text { ( } p \text { value) }\end{array}$} \\
\hline & & $95 \% \mathrm{Cl}$ & 95th percentile & mean $(\mathrm{SD})$ & $95 \% \mathrm{Cl}$ & 95 th percentile & \\
\hline change of $\mathrm{FEV},[\mathrm{ml}]$ & $107.4(130.6)$ & $91.4-123.3$ & 335.3 & $55.9(86.2)$ & $47.1-64.8$ & 214.5 & $<0.001$ \\
\hline change of $\mathrm{FEV}, \%$ from baseline & $3.0(4.3)$ & $2.5-3.5$ & 8.6 & $2.2(3.7)$ & $1.8-2.6$ & 8.4 & 0.009 \\
\hline change of $\mathrm{FEV}_{6}[\mathrm{ml}]$ & $-2.1(137.7)$ & $-18.9-14.8$ & 195.8 & $-21.4(93.5)$ & $-31.0--11.8$ & 144.9 & 0.036 \\
\hline change of $\mathrm{FEV}_{6} \%$ from baseline & $0.1(3.5)$ & $-0.3-0.6$ & 4.8 & $-0.5(3.1)$ & $-0.8--0.2$ & 5.1 & 0.023 \\
\hline change of FVC [ml] & $-35.6(\mid 47.6)$ & $-53.6--17.6$ & 170.2 & $-48.1(100.9)$ & $-58.4--37.8$ & 132.2 & n.s. \\
\hline change of FVC \% from baseline & $-0.6(3.4)$ & $-1.0--0.2$ & 3.6 & $-1.2(3.2)$ & $-1.6--0.9$ & 4.4 & 0.016 \\
\hline change of FET [s] & $-0.1(2.6)$ & $-0.5-0.2$ & 3.2 & $-0.3(2.7)$ & $-0.5-0.0$ & 3.7 & n.s. \\
\hline change of FET \% from baseline & $-0.6(2 \mid .2)$ & $-3.2-2.0$ & 34.7 & $1.2(25.6)$ & $-1.4-3.8$ & 48.6 & n.s. \\
\hline
\end{tabular}

$\mathrm{FEV}_{\mathrm{t}}=$ forced expiratory volume in $\mathrm{t}$ second(s), $\mathrm{FVC}=$ forced vital capacity; $\mathrm{FET}=$ forced expiratory time; $\mathrm{Cl}=$ confidence interval; $\mathrm{n} . \mathrm{s} .=$ not significant

flow limitation the corresponding values were $-0.7 \%$ and $-1.3 \%$. Conversely, there was no significant difference in FET between the subjects with or without airflow limitation at the baseline.

For healthy asymptomatic non-smokers $(\mathrm{n}=219)$, the 95 $5^{\text {th }}$ percentile of change in $\mathrm{FEV}_{6}$ was $112.0 \mathrm{ml}$ and $3.4 \%$, change in FVC $92.0 \mathrm{ml}$ and 2.5\%, and change in FET 3.7 seconds and $50.0 \%$.

\section{Discussion}

The present study indicates that increase of FVC in response to inhaled salbutamol in the bronchodilation test in a general population sample is infrequent and is only rarely associated to increased expiratory time. Amongst subjects with baseline airflow limitation, $\mathrm{FEV}_{6}$ response differentiated those individuals by whom increase of FVC was caused by longer exhalation time. This is important, because it implies that the use of $\mathrm{FEV}_{6}$ would help to remove the need for standardization of exhalation time during standard bronchodilation testing. Decrease of FVC during the bronchodilation test was more frequent than previously reported, especially in healthy subjects. Therefore, the limit of significant increase of FVC might be lower than previously thought. However, the limits of any significant change are dependent of the inherent variability of the measures, like FVC, $\mathrm{FEV}_{6}$ and FET.

Bronchodilation response in flow-volume spirometry is primarily assessed with $\mathrm{FEV}_{1}$, but a significant response can also be seen in other measures, such as FVC [11$13,18,30-32]$. It has been hypothesized that in patients with chronic airflow limitation combined with hyperinflation the potential increase of expiratory airflow due to bronchodilation may be attenuated in small airways due to airway-to-parenchymal interdependence [12]. The degree of obstruction in COPD has been found to modify the spirometric response to bronchodilation; $\mathrm{FEV}_{1}$ response shown to dominate in mild obstruction (GOLD Stage I-II) and FVC response in severe obstruction (GOLD III-IV) [11]. Also in our material from general population FVC response to bronchodilator increased as the postbronchodilator $\mathrm{FEV}_{1} / \mathrm{FVC}$ ratio decreased as shown in Figure 3. However, especially in subjects with airflow limitation FVC has been found to depend on forced expiratory time; longer exhalations potentially created higher FVC values not necessarily due to actual bronchodilation [13]. At the present, FET is not routinely given in the reports of flow-volume spirometry and there is limited information on the concurrent changes of FET and FVC. It has been suggested, but not proved, that an increase in FET during bronchodilation testing in severely obstructed individuals could reflect bronchodilation in small airways $[31,33]$.

Since a positive response in FVC is most often seen in more severe COPD in a bronchodilation test, a large part of the bronchodilation studies assessing changes in lung volumes have been conducted in groups of patients with obstructive pulmonary diseases $[12,14,18,30-32]$. Bronchodilating medication, its dose and mode of delivery have varied making comparisons difficult. Most studies with large number of individuals have been conducted based on patient databases, where the exclusion of untreated asthmatics is nearly impossible [31].

Differing views have been voiced on the interpretation of FVC response. In patients with marked hyperinflation, bronchodilation response has been demonstrated to occur in inspiratory capacity (IC) and residual volume (RV) with better correlation to symptom relief than with other spirometric variables [31,32]. Changes in vital capacity (VC) might in some individuals better correlate with symptomatic relief from bronchodilating medication and FVC can underestimate this volume response [34]. However, when assessing changes measured with flow-volume spirometry, $\mathrm{FEV}_{6}$ would offer a measure that is not influenced by as many pathophysiological factors as 


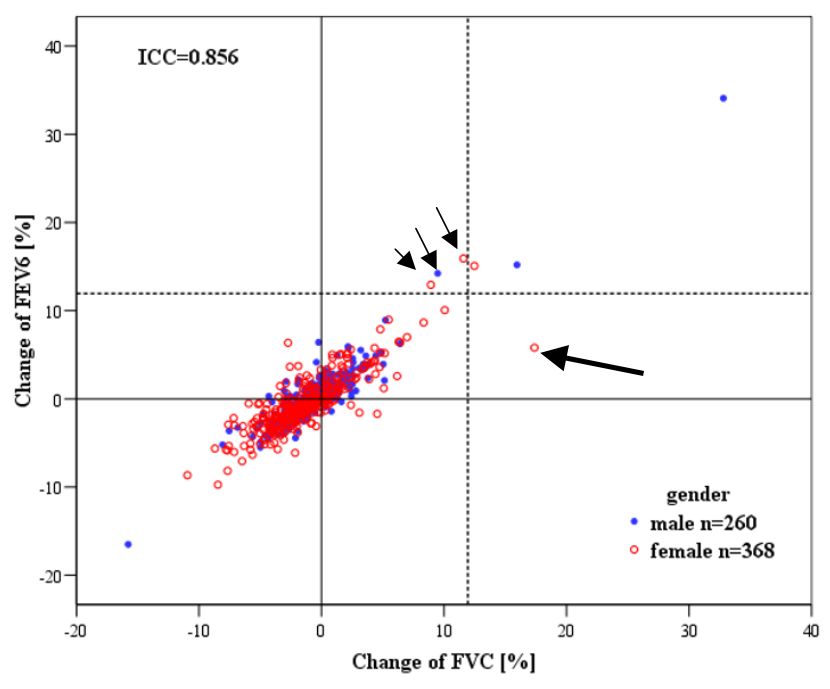

Figure 2

Individual changes of forced vital capacity (FVC) and forced expiratory volume in six seconds $\left(F E V_{6}\right)$ after bronchodilation in the general adult population $(\mathbf{n}=$ 628). The dotted lines represent the significant change limit of $12 \%$ from the baseline [14] for FVC. All subjects with a change over $12 \%$ also fulfilled the absolute change criterion of $200 \mathrm{ml}$. The thick arrow highlights one subject with prolonged post-bronchodilation FET resulting in increase of FVC in the absence of significant change in $\mathrm{FEV}_{6}$. The small arrows show subjects with significantly improved $\mathrm{FEV}_{6}$ in the absence of increase in FVC, caused by shorter exhalations in postbronchodilation spirometry. ICC = intra-class correlation.

FVC. Increase in $\mathrm{FEV}_{6}$ may partially reflect flow changes also in small airways. Variables regarded to represent small airways (MEF50, MMEF) have greater inter- and intra-session variability than $\mathrm{FEV}_{6}[35,36]$ and are affected by concurrent changes in FVC. It is theoretically possible that in subjects with marked peripheral airways obstruction prolongation of FET after bronchodilation could imply decreased hyperinflation.

The frequent negative changes in FVC during bronchodilation test have to date been largely neglected. However, it greatly affects the distribution of values and the assessment of upper limit of normal change. We found $23 \%$ of men and $33 \%$ of women to have greater than $2.5 \%$ reduction in FVC in the bronchodilation test. One reason for reduction of FVC after the bronchodilator in healthy subjects could be the increased collapsibility of the airways as a result of the reduced airway smooth muscle tone with $\beta 2$-agonists [37]. On the contrary, those subjects with markedly reduced $\mathrm{FEV}_{1} / \mathrm{FVC}$ ratio indicating bronchial obstruction showed increased FVC after bronchodilation in our population study (Figure 3, Table 4). In this population, the upper $95^{\text {th }}$ percentiles for change in $\mathrm{FEV}_{6}$ and
FVC were around 5\% and 4\% from baseline, respectively. The corresponding values for the subgroup of healthy asymptomatic non-smokers were $3.4 \%$ and $2.5 \%$.

When considering significant changes in bronchodilation testing, it is necessary to evaluate also the inherent measurement variability. In a large patient sample, the intrasession repeatability of FVC has been shown to have a $95^{\text {th }}$ percentile of $7.0 \%$ or $180 \mathrm{ml} \mathrm{[38]} \mathrm{although} \mathrm{that} \mathrm{study}$ didn't control concurrent variations in FET either. In our earlier report from the present population sample the $95^{\text {th }}$ percentiles of the intra-session repeatability of $\mathrm{FEV}_{6}$ and FVC were $3.3 \%$ or $117 \mathrm{ml}$ and $3.2 \%$ or $119 \mathrm{ml}$, respectively [16]. Concurrently FET varied on average -0.0 (2.0) seconds with a $95^{\text {th }}$ percentile of 2.7 seconds. Earlier, Pennock and coworkers have concluded that the within-day repeatability of FVC is $6.7 \%$ and $\mathrm{FEV}_{1} 8.1 \%$ in obstructive subjects [36]. Although our results imply that an increase in FVC due to bronchodilation is statistically significant at a lower level than given in the current standards [14], the limit for significant change cannot be lower than the repeatability of the measurement.

In our study, very few positive $\mathrm{FEV}_{6}$ or FVC bronchodilation responses were detected in the unselected population sample, which limits the possibilities of further analysis in this study. This can partially be caused by the fact that regular medication was not discontinued for the study and hence subjects with asthma were on appropriate treatment. Since the number of subjects with positive responses was this limited in the population, concurrent changes in $\mathrm{FEV}_{6}, \mathrm{FVC}$, and FET should be further evaluated in subjects with varying degrees of obstruction. However, it is clear from this unselected population study that FVC tends to decrease in the healthy subjects and thus positive changes - most likely in those with airflow obstruction - are significant at a lower level than previously thought. No differences were detected between different age-groups, but the negative changes were slightly more common in women. However, men had more airflow limitation, which was associated with more frequent positive changes in $\mathrm{FEV}_{6}$ and $\mathrm{FVC}$ during the bronchodilation test.

$\mathrm{FEV}_{6}$ performed in this study comparably with FVC, suggesting that it could be considered a surrogate for FVC in the bronchodilation test. FVC might underestimate changes in vital capacity (VC) in subjects with severe airflow limitation and air trapping, which has been suggested to partially account for their subjective benefit of bronchodilating medication in clinical practice [34]. In subjects with airflow limitation, change in $\mathrm{FEV}_{6}$ was significant in three subjects that had shorter exhalations in post-bronchodilation spirometry, which resulted in changes in FVC remaining below significant change limits 
Table 3: Data of subjects with significant changes in forced expiratory volume in six seconds $\left(F_{6} V_{6}\right.$ ) or forced vital capacity (FVC) in the bronchodilation test

\begin{tabular}{|c|c|c|c|c|c|c|c|c|c|c|c|c|c|}
\hline \multirow{2}{*}{$\begin{array}{l}\text { age } \\
\text { [yrs] }\end{array}$} & \multirow[t]{2}{*}{ gender } & \multirow{2}{*}{$\begin{array}{c}\mathrm{FEV}_{1} / \mathrm{FVC} \text { post } \\
{[\%]}\end{array}$} & \multirow{2}{*}{$\begin{array}{l}\text { FEV } \\
\text { post } \\
{[\% *]}\end{array}$} & \multirow{2}{*}{$\begin{array}{l}\text { smoking status } \\
\text { [pack-years] }\end{array}$} & \multirow[t]{2}{*}{ history of OAD } & \multicolumn{2}{|c|}{ change in FVC } & \multicolumn{2}{|c|}{ change in $\mathrm{FEV}_{6}$} & \multicolumn{2}{|c|}{ change in FET } & \multicolumn{2}{|c|}{ change in $\mathrm{FEV}$, } \\
\hline & & & & & & $\mathrm{ml}$ & $\%$ & $\mathrm{ml}$ & $\%$ & s & $\%$ & $\mathrm{ml}$ & $\%$ \\
\hline 52.9 & $\mathrm{~m}$ & $48.9 \%$ & $62.1 \%$ & $\begin{array}{l}\text { current smoker } \\
22.2\end{array}$ & asthma & 1183 & 32.8 & 979 & 34,1 & 0.3 & 1.5 & 573 & 32.4 \\
\hline 50.5 & $w$ & $55.5 \%$ & $59.7 \%$ & $\begin{array}{l}\text { current smoker } \\
33.0\end{array}$ & $\begin{array}{c}\text { no dg } \\
\text { no med }\end{array}$ & 350 & 11.6 & 424 & 15.9 & -1.2 & -10.1 & 381 & 25.5 \\
\hline 67.8 & $\mathrm{~m}$ & $44.7 \%$ & $51.4 \%$ & $\begin{array}{l}\text { former smoker } \\
35.0\end{array}$ & COPD & 557 & 16.0 & 446 & 15.2 & 2.9 & 22.1 & 321 & 21.6 \\
\hline 47.5 & $w$ & $50.0 \%$ & $51.9 \%$ & $\begin{array}{l}\text { current smoker } \\
52.2\end{array}$ & asthma & 350 & 12.5 & 336 & I5.I & -1.7 & -9.2 & 246 & 18.5 \\
\hline 63.0 & $\mathrm{~m}$ & $38.7 \%$ & $46.9 \%$ & $\begin{array}{l}\text { current smoker } \\
84.0\end{array}$ & $\begin{array}{l}\text { no dg asthma } \\
\text { med }\end{array}$ & 353 & 9.5 & 418 & 14.2 & -1.3 & -7.8 & 241 & I8.1 \\
\hline 52.6 & $w$ & 78.4 & 79.3 & $\begin{array}{l}\text { non-smoker } \\
0.0\end{array}$ & asthma & 240 & 8.9 & 329 & 12.9 & -4.5 & -34.5 & 364 & 18.8 \\
\hline 52.4 & $w$ & $43.1 \%$ & $45.0 \%$ & $\begin{array}{l}\text { former smoker } \\
14.0\end{array}$ & asthma & 378 & 17.4 & 107 & 5.8 & 8.0 & 70.7 & 109 & 11.0 \\
\hline
\end{tabular}

$\mathrm{FEVI}$ = forced expiratory volume in one second; FVC = forced vital capacity; OAD = obstructive airways disease; FEV 6 = forced expiratory volume in six seconds; $\mathrm{FET}$ = forced expiratory time; $\mathrm{dg}$ = diagnosis; med = medication.

$*$ of predicted values from [24]

(Table 3). We chose to replace $\mathrm{FEV}_{6}$ with FVC when FET was under 6 seconds, because the exclusion of these subjects would have created a selection bias. In subjects with FET $<6$ seconds, most often healthy young adults, FVC is not dependent on FET [39]. The intra-class correlation coefficient showed good agreement between changes in $\mathrm{FEV}_{6}$ and FVC especially in subjects with airflow limitation in spirometry. Earlier Girard \& Light have also shown that timed expiratory flows $\left(\mathrm{FEV}_{3}\right.$ and $\left.\mathrm{FEV}_{6}\right)$ generally increase if the increase in FVC is not being caused by longer FET [13]. Previously it has been reported that $\mathrm{FEV}_{6}$ has the least within-session variability of the FEVx values [17] when exhalation times are over 10 seconds. It is suggested that the use of $\mathrm{FEV}_{6}$ would preclude the need to standardize FET and could act as a measure of bronchodilation especially in the primary care. The current standard
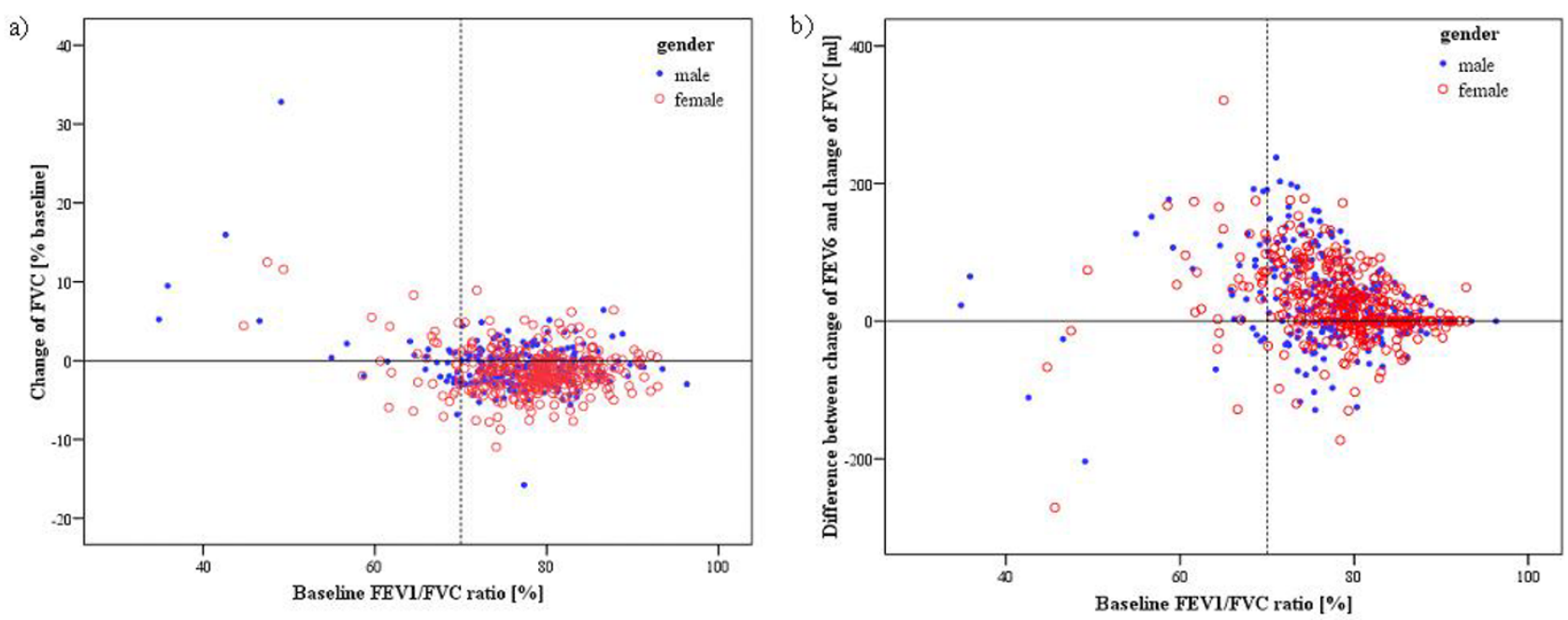

Figure 3

The relationship of a) individual changes in forced vital capacity (FVC) after bronchodilation, and b) the difference between the individual changes in forced expiratory volume in six seconds $\left(F^{2} V_{6}\right)$ and FVC, to the ratio of forced expiratory volume in one second $\left(F E V_{1}\right)$ to $F V C$ at the baseline in general adult population $(n=628)$. The dotted line indicates the $\mathrm{FEV}_{1} / \mathrm{FVC}$ limit for airflow obstruction (0.7). In subjects with airflow obstruction, positive FVC bronchodilation response was more common and the difference between FVC and $\mathrm{FEV}_{6}$ responses tended to be larger. 
Table 4: Change in flow-volume spirometry variables in subjects with and without airflow limitation at the baseline in the population sample

\begin{tabular}{|c|c|c|c|c|}
\hline & & $\begin{array}{c}\mathrm{FEV}_{\mathrm{l}} / \mathrm{FVC} \geq \mathrm{LLN}^{*} \\
(\mathrm{n}=537) \\
\text { mean }(\mathrm{SD})\end{array}$ & $\begin{array}{c}\mathrm{FEV}_{\mathrm{l}} / \mathrm{FVC}<\mathrm{LLN} * \\
(\mathrm{n}=9 \mathrm{I}) \\
\text { mean (SD) }\end{array}$ & $P$ value \\
\hline \multirow{2}{*}{ change of $\mathrm{FEV}_{\mathrm{l}}(\mathrm{ml})$} & & $66.2(99.9)$ & | 42.6 (139.1) & $P<0.001$ \\
\hline & (\% from baseline) & $1.9(2.9)$ & $6.2(6.4)$ & $\mathrm{p}<0.001$ \\
\hline \multirow[t]{2}{*}{ change of $\mathrm{FEV}_{6}(\mathrm{ml})$} & & $-27.3(98.0)$ & $68.8(160.1)$ & $p<0.001$ \\
\hline & (\% from baseline) & $-0.7(2.5)$ & $2.4(5.4)$ & $\mathrm{P}<0.001$ \\
\hline \multirow[t]{2}{*}{ change of FVC (ml) } & & $-52.8(103.2)$ & I5.4 (192.3) & $\mathrm{p}<0.001$ \\
\hline & (\% from baseline) & $-1.3(2.6)$ & $0.8(5.6)$ & $p<0.001$ \\
\hline \multirow[t]{2}{*}{ change of FET (s) } & & $-0.2(2.5)$ & $-0.4(3.5)$ & $P=0.563$ \\
\hline & (\% from baseline) & $0.8(24.1)$ & $-1.6(22.3)$ & $p=0.370$ \\
\hline
\end{tabular}

$\mathrm{FET}=$ forced expiratory time; $\mathrm{FEV}_{1}=$ forced expiratory volume in one second; $\mathrm{FEV}_{6}=$ forced expiratory volume in six seconds; $\mathrm{FVC}=$ forced vital capacity; LLN = lower limit of normal

* predicted values from [24]

states that FET should be analysed from those curves where the sum of FVC and $\mathrm{FEV}_{1}$ is the greatest [25]. Since FET varies within test session more than FVC and FEV $_{1}$ $[16]$, we suggest that in the bronchodilation test FET should be analysed from those curves with the largest FVC values. $\mathrm{FEV}_{6}$ is more repeatable than $\mathrm{FVC}$ also in subjects with reduced $\mathrm{FEV}_{1} / \mathrm{FVC}[15]$. Earlier it has been disputed that the use of $\mathrm{FEV}_{6}$ could more easily misclassify subjects with borderline obstruction $[4,5,7,8,40]$, but since positive changes in FVC in the bronchodilation test are more likely to occur in more severe airflow limitation, this should not become a problem for the use of $\mathrm{FEV}_{6}$ as a measure of bronchodilation in lieu of FVC.

In conclusion, we found that in a general population sample, positive $\mathrm{FVC}$ and $\mathrm{FEV}_{6}$ response to bronchodilation in flow-volume spirometry was infrequent occurring almost solely in subjects with bronchial airflow limitation. In subjects with normal $\mathrm{FEV}_{1} / \mathrm{FVC}$ ratio both $\mathrm{FVC}$ and $\mathrm{FEV}_{6^{\prime}}$ on the average, decreased. We suggest that $\mathrm{FEV}_{6}$ could be used in assessment of bronchodilation response in flowvolume spirometry instead of FVC; significant increase of $\mathrm{FEV}_{6}$ would seem to be around $6 \%$. By using $\mathrm{FEV}_{6}$ for assessment of bronchodilator effect instead of FVC would remove the need for regulation of forced exhalation time during a bronchodilation test.

\section{Abbreviations}

ATS: American Thoracic Society; ANOVA: analysis of variance; BMI: body mass index; $\mathrm{CI}$ : confidence interval; COPD: chronic obstructive pulmonary disease; ERS: European Respiratory Society; FET: forced expiratory time; FEVx: forced expiratory volume in $\times$ seconds; FVC: forced vital capacity; GOLD: Global Initiative for Chronic Obstructive Lung Disease; IC: Inspiratory capacity; ICC: intra-class correlation coefficient; LLN: lower limit of normal; MEF50: maximal instantaneous forced expiratory flow where $50 \%$ of FVC remains to be expired; MMEF: maximum mid-expiratory flow; OLIN: Obstructive Lung Disease in Northern Sweden Study; PEF: peak expiratory flow; RV: residual volume.

\section{Competing interests}

The authors declare that they have no competing interests.

\section{Authors' contributions}

AK has conducted the data processing and statistical analyses with consultative help from SS. AK has mainly drafted the text and illustrations of the article, with editorial advice from $\mathrm{BL}, \mathrm{AL}$ and $\mathrm{AS}$, who also have contributed to the text. All authors have read and approved the final manuscript.

\section{Acknowledgements}

The FinEsS-Helsinki study has been funded from Helsinki University Central Hospital special governmental subsidy TYH I235, TYH 2303, and TYH

425I. A.K. was funded by grants from Ida Montin Foundation, The Finnish Lung Foundation (HELI), Foundation of the Finnish Anti-Tuberculosis Association and Helsinki University Central Hospital special governmental subsidy research grant.

\section{References}

I. Ferguson GT, Enright PL, Buist AS, Higgins MW: National Lung Health Education Program (NLHEP). Office spirometry for lung health assessment in adults: a consensus statement from the National Lung Health Education Program. Chest 2000, II7:1146-II6I.

2. Swanney MP, Jensen RL, Crichton DA, Beckert LE, Cardno LA, Crapo RO: FEV6 is an Acceptable Surrogate for FVC in the Spirometric Diagnosis of Airway Obstruction and Restriction. Am J Respir Crit Care Med 2000, 162:917-919.

3. Enright PL, Connett JE, Bailey WC: The FEVI/FEV6 predicts lung function decline in adult smokers. Respiratory Medicine 2002, 96:444-449.

4. Akpinar-Elci M, Fedan KB, Enright PL: FEV6 as a surrogate for FVC in detecting airways obstruction and restriction in the workplace. Eur Respir J 2006, 27:374-7.

5. Hankinson JL, Crapo RO, Jensen RL: Spirometric Reference Values for the 6-s FVC Maneuver. Chest 2003, I 24: I805-I8II.

6. Garcia-Rio F, Pino JM, Dorgham A, Alonso A, Villamor J: Spirometric reference equations for European females and males aged 65-85 yrs. Eur Respir J 2004, 24:397-405. 
7. Hansen JE, Sun X-G, Wasserman K: Should forced expiratory volume in six seconds replace forced vital capacity to detect airway obstruction? Eur Respir J 2006, 27: 1244-1250.

8. Vandevoorde J, Verbanck S, Schuermans D, Kartounian J, Vincken W: FEVI/FEV6 and FEV6 as an Alternative for FEVI/FVC and FVC in the Spirometric Detection of Airway Obstruction and Restriction. Chest 2005, 127:1560-1564.

9. Vandevoorde J, Verbanck S, Schuermans D, Broekaert L, Devroey D, Kartounian J, Vincken W: Forced vital capacity and forced expiratory volume in six seconds as predictors of reduced total lung capacity. Eur Respir J 2008, 3 I:391-395.

10. Rabe KF, Hurd S, Anzueto A, Barnes PJ, Buist SA, Calverley P, Fukuch Y, Jenkins C, Rodriquez-Roisin R, van Weel C, Zielinski J: Global Strategy for the Diagnosis, Management, and Prevention of Chronic Obstructive Pulmonary Disease. GOLD Executive Summary. Am J Respir Crit Care Med 2007, I 76:532-555.

II. Schermer T, Heijdra $Y$, Zadel S, Bemt $L$ van den, Boonman-de Winter $\mathrm{L}$, Dekhuijzen R, Smeele I: Flow and volume responses after routine salbutamol reversibility testing in mild to very severe COPD. Respir Med 2007, 10 I:1355-1362.

12. Cerveri I, Pellegrino R, Dore R, Corsico A, Fulgoni P, Woestijne KP van de, Brusasco $V$ : Mechanisms for isolated volume response to a bronchodilator in patients with COPD. J Appl Physiol 2000 , 88:1989-1995.

13. Girard WM, Light RW: Should the FVC be considered in evaluating response to bronchodilator? Chest 1983, 84:87-89.

14. Pellegrino R, Viegi G, Brusasco V, Crapo RO, Burgos F, Casaburi R, Coates A, Grinten CPM van der, Gustafsson P, Hankinson J, Jensen R, Johnson DC, Maclntyre N, McKay R, Miller MR, Navajas D, Pedersen $\mathrm{OF}, \mathrm{Wanger} \mathrm{J}$ : Interpretative strategies for lung function tests. Eur Respir J 2005, 26:948-968.

15. Kainu A, Lindqvist A, Sarna S, Lundbäck B, Sovijärvi A: FEVI response to bronchodilation in an adult urban population and in healthy adults. Chest 2008, 134:387-393.

16. Kainu A, Lindqvist A, Sarna S, Sovijärvi A: Intra-session repeatability of FET and FEV6 in the general population. Clin Phys Funct Imag 2008, 28:|96-20|.

17. Jensen RL, Crapo RO, Enright P, Others From the Family Heart Study: A Statistical Rationale for the Use of Forced Expiratory Volume in 6s. Chest 2006, 130:1650-1656.

18. Light RW, Conrad SA, George RB: The one best test for evaluating the effects of bronchodilator therapy. Chest 1977, 72:512-516.

19. Pallasaho P, Rönmark E, Haahtela T, Sovijärvi ARA, Lundbäck B: Degree and clinical relevance of sensitization to common allergens among adults: a population study in Helsinki, Finland. Clin Exp All 2006, 36:503-509.

20. Kainu A: Spirometric studies on the adult general population of Helsinki-bronchodilation responses, determinants, and intrasession repeatability of FEVI, FEV6, FVC, and forced expiratory time A report from the FinEsS-Helsinki II study. University of Helsinki Thesis 2008:84-98.

21. Lundbäck B: Asthma, chronic bronchitis and respiratory symptoms: prevalence and important determinants. The Obstructive Lung Disease in Northern Sweden Study I. Umea University Medical Dissertations 1993, 387: I-I I8. Appendix: i-xii

22. American Thoracic Society: Standardisation of Spirometry. 1994 Update. Am J Respir Crit Care Med 1995, I 52: I I07-I I 36.

23. Quanjer Ph H, Tammeling G], Coters JE, Pedersen OF, Peslin R, Yernault J-C: Lung Volumes and Forced Ventilatory Flows. Report Working Party. Official Statement of the European Respiratory Society. Eur Respir J 1993, 6(Suppl 16):5-40.

24. Viljanen AA, Halttunen PK, Kreus K-E, Viljanen BC: Spirometric studies in non-smoking, healthy adults. Scand I Clin Lab Invest 1982, 42:5-20.

25. Miller MR, Hankinson J, Brusasco V, Burgos F, Casaburi R, Coates A, Crapo $R$, Enright $P$, Grinten CPM van der, Gustafsson $P$, Jensen $R$, Johnson DC, Maclntyre N, McKay R, Navajas D, Pedersen OF, Pellegrino R, Viegi G, Wanger J: Series "ATS/ERS Task Force: Standardisation of Lung Function Testing". Standardisation of spirometry. Eur Respir J 2005, 26:319-338.

26. Shrout PE, Fleiss JL: Intraclass correlations: Uses in assessing rater reliability. Psychological Bulletin 1979, 86:420-428.

27. McGraw KO, Wong SP: Forming inferences about some intraclass correlation coefficients. Psychological Methods 1996, I:30-46.
28. Bland JM, Altman DG: Statistical methods for assessing agreement between two methods of clinical measurement. Lancet 1986, i:307-310.

29. Chinn S: Repeatability and method comparison. Statistics in respiratory medicine. Thorax 1991, 46:454-456.

30. Ramsdell JW, Tisi GM: Determination of bronchodilation in the clinical pulmonary function laboratory. Role of changes in static lung volumes. Chest 1979, 76:622-628.

31. Newton MF, O'Donnell DE, Forkert L: Response of lung volumes to inhaled salbutamol in a large population of patients with severe hyperinflation. Chest 2002, I 21 : 1042-1050.

32. Pellegrino R, Rodarte JR, Brusasco V: Assessing the reversibility of airway obstruction. Chest 1998, II4:1607-16/2.

33. Tsai AG, Christie JD, Gaughan CA, Palma WR Jr, Margolis ML: Change in Forced Expiratory Time and Spirometric Performance During a Single Pulmonary Function Testing Session. Respir Care 2006, 5 I:246-25I.

34. Tweeddale PM, Alexander F, McHardy GJR: Short term variability in $F E V_{1}$ and bronchodilator responsiveness in patients with obstructive ventilatory defects. Thorax 1987, 42:487-490.

35. Cochrane GM, Prieto F, Clark TJH: Intrasubject variability of maximal expiratory flow volume curve. Thorax 1977, 32:17|-176.

36. Pennock BE, Rogers RM, McCaffree DR: Changes in measured spirometric indices. What is significant? Chest I98I, 80:97-99.

37. Fairshter RD, Wilson AF: Response to inhaled metaproterenol and isoproterenol in asthmatic and normal subjects. Chest 1980, 78:44-50.

38. Enright PL, Beck KC, Sherrill DL: Repeatability of spirometry in 18,000 adult patients. Am J Respir Crit Care Med 2004, 169:235-238.

39. Leith $D E$, Mead J: Mechanisms determining residual volume of the lungs in normal subjects. J Appl Physiol 1967, 23:22I-227.

40. Vandevoorde J, Swanney $M$ : Is forced expiratory volume in six seconds a valid alternative to forced vital capacity? [Letter]. Eur Respir J 2006, 28: 1288-1289.

Publish with Bio Med Central and every scientist can read your work free of charge

"BioMed Central will be the most significant development for disseminating the results of biomedical research in our lifetime. "

Sir Paul Nurse, Cancer Research UK

Your research papers will be:

- available free of charge to the entire biomedical community

- peer reviewed and published immediately upon acceptance

- cited in PubMed and archived on PubMed Central

- yours - you keep the copyright 